\title{
Quality of life in caregivers of patients with bipolar mood disorder with current manic episode and its correlation with severity of illness
}

\author{
Sanjibani Panigrahi ${ }^{1}$, Rajendra Kumar Acharya ${ }^{2}$, Mukesh K Patel ${ }^{3}$, Kalpesh V \\ Chandrani ${ }^{4}$ \\ 1,2,3,4, Department of Psychiatry, PDU Medical College, Rajkot, India
}

\begin{abstract}
With the advent of deinstitutionalization there is increasing interest in the quality of life of caregivers of patients with bipolar mood disorder all over the world. Quality of life of 50 caregivers of bipolar mood disorder (with current manic episode) patients were evaluated using $Q-L E S-Q-S F$. Severity of manic episode was evaluated using YMRS scale. Quality of life was found to be moderately low. Parents of patients had the poorest quality of life compared to caregivers in other relationships. Quality of life in caregivers was negatively correlated with YMRS score.
\end{abstract}

Keywords: Bipolar Mood Disorder, Caregivers, Manic episode, Quality of Life, YMRS Score

\section{Introduction}

The role of the mental hospital in patient population peaked in the 50's and has since declined. Over the last thirty years the world has accepted, indeed advocated, that the community rehabilitation approach provides the most appropriate means for dealing with mentally ill people. This has involved a multitude of initiatives, including the development of psychiatric units in district general hospitals, increased emphasis upon providing psychiatric services in primary care settings, the development of residential and day care facilitates, and an increased emphasis on the role of voluntary groups, friends, relatives and neighbors in the provision of care for people with mental disorders in the community.

Bipolar disorder is a recurrent and long term mental illness that can seriously affect the lives of patients and their relatives. It is characterized by the alternating occurrence of manic, hypomanic, depressive and mixed episodes. Bipolar disorder has been ranked ninth among the worldwide causes of non fatal disease burden for people of all ages and ranked fifth for people between 15 and 44 years of age (World Health Organisation, 2001). There are high rates of recurrence associated with these disorders, and residual symptoms between major episodes are common [1]. This is true even for those receiving treatment.

Traditional estimates suggest bipolar disorders affect about 5.7 million Americans in any given year, or about $2.6 \%$ of the US population (National Institute of Mental Health, 2010). A recent large-scale epidemiological survey, the National Comorbidity Survey Replication [2] reported a 3.9 percent lifetime prevalence of bipolar I and II disorders. Other studies, however, have found prevalence rates as high as $8 \%$ [3]. India has a prevalence of 0.1 percent.

But very few studies from India have been done on the quality of life of caregivers of bipolar mood disorder patients [4], [5], [6], [7], [8]. Considering the increasing interest in the quality of life of caregivers of patients of bipolar mood disorder all over the world, we thought that this study will be fruitful in understanding quality of life of such caregivers in our cultural setup. The present study is an effort in this direction and is designed to assess the quality of life of caregivers of bipolar mood disorder patients and find its correlation with the severity of illness.

\section{Materials And Methods}

This is a cross- sectional study in clinical setting without use of any normal control group. The study was done during the period from June 2013 to March 2014.

All the consecutive indoor patients with bipolar mood disorder (BMD) with current manic episode (diagnosed as per DSM IV- TR) in Department of Psychiatry, PDU Medical College, Rajkot (which is a tertiary care centre) and their caregivers were taken for study between the 3rd to 5th day of admission. Totally 50 patients with BMD mania and their 50 caregivers ( 1 caregiver for each patient) were taken. They were explained about the nature of the study. Informed written consent was taken. Quality of life of caregivers was determined using Quality of Life Enjoyment and Satisfaction Questionnaire- Short Form (Q-LES-Q-SF). Severity of manic episode was assessed using Young Mania Rating Scale (YMRS).

SPSS version 17.0 was used to analyse data. Data was analysed for statistical significance with chi square test and t-test as the case may be. Probability value less than 0.05 has been taken as statistically 
significant. Pearson correlation was used to find out correlation between quality of life and severity of illness. Correlation was considered significant at the 0.01 level (2-tailed).

\section{Results}

Table 1 shows the socio-demographic characteristics of BMD mania patients. Mean age of patients was 41.50 years. $68 \%$ of the patients were males while $32 \%$ were females. $42 \%$ of the patients resided in urban areas, $26 \%$ in semi-urban areas and $32 \%$ in rural areas.

Table 1: Socio-demographic Characteristics of Schizophrenia Patients

\begin{tabular}{|c|c|}
\hline Patients & $\begin{array}{c}\text { Bipolar Mood Disorder } \\
\mathrm{N}=50(\%)\end{array}$ \\
\hline Age (years) & \\
Mean & 41.50 \\
\hline Sex & $\mathrm{N}(\%)$ \\
Male & $34(68)$ \\
Female & $16(32)$ \\
\hline Domicile & $\mathrm{N}(\%)$ \\
Urban & $21(42)$ \\
Semi-urban & $13(26)$ \\
Rural & $16(32)$ \\
\hline
\end{tabular}

Table 2 shows the socio-demographic characteristics of caregivers of BMD mania patients. Mean age of caregivers was 44.70 years. $68 \%$ of the caregivers were males while $32 \%$ were females. $26 \%$ of the caregivers were parents to the patients, $48 \%$ were spouses while $26 \%$ were in other relationships with the patients.

Table 2: Socio-Demographic Characteristics of Caregivers

\begin{tabular}{|c|c|}
\hline Caregivers & $\begin{array}{c}\text { Bipolar Mood Disorder } \\
\mathrm{N}=50(\%)\end{array}$ \\
\hline Age (years) & 44.70 \\
Mean & $\mathrm{N} \mathrm{( \% )}$ \\
\hline Sex & $34(68)$ \\
Male & $16(32)$ \\
\hline Female & $\mathrm{N}(\%)$ \\
Relationship with Patient & $13(26)$ \\
Parents & $24(48)$ \\
Othouse & $13(26)$ \\
& \\
\hline
\end{tabular}

Table 3 shows the clinical variables of patients. The mean duration of illness was 11.06 years and the mean age at onset of illness was 29.98 years.

Table 3: Clinical Variables of Patients

\begin{tabular}{|c|c|}
\hline Patients & $\begin{array}{c}\text { Bipolar Mood Disorder } \\
\mathrm{N}=50(\%)\end{array}$ \\
\hline $\begin{array}{c}\text { Duration of Illness (years) } \\
\text { Mean Duration }\end{array}$ & 11.06 \\
\hline $\begin{array}{c}\text { Age at onset (years) } \\
\text { Mean }\end{array}$ & 29.98 \\
\hline
\end{tabular}

Table 4 shows the quality of life in caregivers. The mean Q-LES-Q-SF score was 48.28.

Table 4: Quality of Life in Caregivers

\begin{tabular}{|c|c|}
\hline Q-LES-Q-SF score & Bipolar Mood Disorder \\
& $\mathrm{N}=50$ \\
\hline Mean (SD) & $48.28(8.887)$ \\
\hline
\end{tabular}

Table 5 shows caregiver's quality of life and relationship with patient. Q-LES-Q-SF score for parents was the lowest at 45.23. Q-LES-Q-SF score for spouses was 47.29 and for caregivers in other relationships it was 53.15. Parents had a statistically significant poorer quality of life when compared to caregivers in other relationships. 
Table 5: Caregiver's Quality of Life and Relationship with Patient

\begin{tabular}{|c|c|}
\hline Relationship with Patient & $\begin{array}{c}\text { Bipolar Mood Disorder } \\
\text { Q-LES-Q-SF Score } \\
\text { Mean (SD) } \\
\mathrm{N}=50\end{array}$ \\
\hline Spouse & $47.29(9.827)$ \\
\hline Parents & $45.23(8.115)$ \\
\hline Others & $53.15(5.814)$ \\
\hline Test of & $\mathrm{t}=0.645, \mathrm{p}=0.523, \mathrm{NS}$ \\
\hline Significance & $\mathrm{t}=-1.965, \mathrm{p}=0.057, \mathrm{NS}$ \\
\hline Spouse Vs Parents & $\mathrm{t}=-2.861, \mathrm{p}=0.009, \mathrm{~S}$ \\
\hline
\end{tabular}

\section{NS= Not Significant, $S=$ Significant}

Table 6 shows correlation of bipolar mood disorder caregiver's quality of life with YMRS Scores. Pearson Correlation was used to correlate Q-LES-Q-SF Score in caregivers and YMRS scores in bipolar mood disorder patients. Quality of life in caregivers of bipolar mood disorder patients had statistically significant negative correlation $(\mathrm{p}=0.000)$ with YMRS score.

Table 6: Correlation of Bipolar Mood Disorder Caregiver's Quality of Life with YMRS Score

\begin{tabular}{|r|c|c|}
\hline Variable & Correlation Type & YMRS Score \\
\hline Q-LES-Q-SF Score & Pearson Correlation & $-0.481(* *)$ \\
\hline & Sig. (2-tailed) & 0.000 \\
\hline & $\mathrm{N}$ & 50 \\
\hline
\end{tabular}

\section{Discussion}

Quality of life in caregivers is inversely related to their burden. Alejandra Caqueo-Urízar et al [9] reported decreased QOL to be associated with caregivers' burden. Selwyn Stanley et al [10] and Anniqa Foldemo et al [11] obtained a significant negative correlation between the family burden and QOL scores of the caregiver indicating that these two dimensions mutually influence one another.

Mean Q-LES-Q-SF score represents quality of life in caregivers. In our study we found quality of life to be moderately low in the caregivers. This is similar to the findings by Allison M. R. Lee et al [12], Perlick DA et al [13], , M. Reinares et al [14], Ogilvie AD et al [15], Heru AM et al [16], S.Chakrabarti et al [6], D Perlick et al [17] who have reported moderate to high levels of burden among caregivers of Bipolar patients.

Also when we compare the Quality of Life of parents with spouses, we find that they have a similar Quality of Life ( $\mathrm{p}=0.523)$. This finding is consistent with the findings of K.K.Ganguly et al [4] who found that spouses and parents had similar burden. Parents had a statistically significant $(\mathrm{p}=0.009)$ poorer Quality of Life when compared to caregivers in other relationships (children, sibling). Similarly, Aschbrenner KA et al [18] found parents to have a very high degree of burden and Awadalla AW et al [19] found parents to have least QOL scores.

Quality of life in caregivers of bipolar mood disorder patients had statistically significant negative correlation $(\mathrm{p}=0.000)$ with YMRS score. Similar findings have been reported by a number of studies. Rita Bauer et al [20] found that manic symptoms of the ill family members emerged as serious burdens on the caregivers. Findings from Eduard Vieta et al [21] revealed that up to $93 \%$ of caregivers of bipolar patients suffered from a moderate or higher level of stress when the patient was admitted to an inpatient unit or outpatient clinic. Perlick DA et al [13] found that $89 \%, 52 \%$, and $61 \%$ of caregivers, respectively, experienced moderate or higher burden in relation to patient problem behaviors, role dysfunction, or disruption of household routine. S.Chakrabarti et al [17], T Y G Van Der Voort et al [22] found severity of illness among patients to be correlated consistently with severity of burden in caregivers. M. Reinares et al [14] reported that caregiver's highest subjective burden was associated with patient's hyperactivity and irritability. Ritu Nehra et al [5] found high levels of patientdysfunction gave rise to higher caregiver-burden. Mueser KT et al [23] reported that relatives of patients with bipolar disorder rated manic symptoms as burdensome. 


\section{Conclusion}

Our study suggests that quality of life is moderately low in caregivers of bipolar mood disorder patients. Quality of life of parents is poorer as compared to caregivers in other relationships. Quality of life of caregivers is inversely related to severity of illness. This study suggests that taking care of caregivers is quite important to improve their overall quality of life.

Some of the methodological limitations of the present work need to be mentioned here. The major limitation of this study is its cross-sectional nature. We have studied the quality of life only during the acute phase of the illness. As bipolar mood disorder tends to be chronic with many remissions and relapses we can't comment on the overall quality of life of the caregivers. Also we have studied only the manic phase of Bipolar Disorder. So we can't comment on the quality of life of caregivers in the depressive phase of the illness.

We have conducted the study on the caregivers of only indoor patients. These caregivers may not be representative of all the caregivers in the community, particularly those who have no access to mental health care. Also we have conducted the study only on 50 caregivers. A larger sample size is needed to comment more accurately on the quality of life of caregivers.

To get a more accurate idea of quality of life of caregivers of Bipolar Mood Disorder patients large scale community based longitudinal study of such caregivers can be helpful.

\section{References}

[1] Judd LL, Schettler PJ, Akiskal HS, Maser J, Coryell W, Solomon D, Endicott J, Keller M, Long-term symptomatic status of bipolar I vs. bipolar II disorders, Int. J.Neuropsychopharmacol., 6, 2003, 127-37.

[2] Kessler RC, Berglund P, Demler O, Jin R, \& Walters EE, Lifetime Prevalence and Age-of-Onset Distributions of DSM-IV Disorders in the National Comorbidity Survey Replication, Archives of General Psychiatry, 62, 2005, 593-602.

[3] Angst J, The emerging epidemiology of hypomania and bipolar II disorder, Journal of Affective Disorders, 50, 1998, $143-151$.

[4] Ganguly KK, Chadda RK\& Singh TB, Caregiver Burden and Coping in Schizophrenia and Bipolar Disorder: A Qualitative Study, American Journal of Psychiatric Rehabilitation, 13:2, 2010, 126-142.

[5] Nehra R, Chakrabarti S, Kulhara P, Sharma R, Caregiver-coping in bipolar disorder and schizophrenia--a re-examination, Soc Psychiatry Psychiatr Epidemiol., 40(4), 2005, 329-36.

[6] Chakrabarti S, Gill S, Coping and its correlates among caregivers of patients with bipolar disorder: a preliminary study. Bipolar Disord., Feb,4(1), 2002, 50-60.

[7] Chakrabarti S, Raj L, Kulhara P, Avasthi A, Verma SK, Comparision of the extent and pattern of Family Burden in Affective Disorders and Schizophrenia. Indian J. Psychiat., 37(3), 1995, 105-112.

[8] Chakrabarti S, Kulhara P, Verma SK, Extent and determinants of burden among families of patients with affective disorders, Acta Psychiatrica Scandinavica, 86(3), 1992, 247-252.

[9] Alejandra Caqueo-Urízar, José Gutiérrez-Maldonado and Claudia Miranda-Castillo, Quality of life in caregivers of patients with schizophrenia: A literature review, Health and Quality of Life Outcomes, 7(84), 2009.

[10] Selwyn Stanley, Quality of Life and family Burden in Caregivers of Patients with Schizophrenia: A study from India, Schizophrenia Research 102(1-3), 2008, 1-279.

[11] Anniqa Foldemo, Mats Gullberg, Anna-Christina Ek, Lennart Bogren, Quality of life and burden in parents of outpatients with schizophrenia, Soc Psychiatry Psychiatr Epidemiol, 40, 2005, 133-138.

[12] Allison M. R. Lee, Daphne Simeon, Lisa J. Cohen, Janine Samuel, Annie Steele, and Igor I. Galynker, Predictors of Patient and Caregiver Distress in an Adult Sample With Bipolar Disorder Seeking Family Treatment, J Nerv Ment Dis, 199, 2011, 18-24.

[13] Perlick DA, Rosenheck R, Miklowitz D, Chessick C, Wolff N, Kaczynski R, Prevalence and correlates of burden among caregivers of patients with bipolar disorder enrolled in the Systematic Treatment Enhancement Program for Bipolar Disorder, Bipolar Disorders, 9(3), 2007, 262-273.

[14] Reinares M, Vieta E, Colom F, Martínez-Arán A, Torrent C, Comes M, Goikolea JM, Benabarre A, Daban C, Sánchez-Moreno J, What really matters to bipolar patients' caregivers: Sources of family burden, Journal of Affective Disorders, 94, $2006,157-163$.

[15] Ogilviea AD, Morantb N and Goodwin GM, The burden on informal caregivers of people with bipolar disorder, Bipolar Disorders $7(1), 2005,25-32$.

[16] Heru AM, Ryan CE \& Vlastos K, Quality of Life and Family Functioning in Caregivers of Patients with Mood Disorders, Psychiatric Rehabilitation Journal 28, 2004, 67-71.

[17] Perlick DA, Clarkin JF, Sirey J, Raue P,Greenfield S, Struening E and Rosenheck R, Burden experienced by care-givers of persons with bipolar affective disorder. The British Journal of Psychiatry, 175, 1999, 56-62.

[18] Aschbrenner KA, Greenberg JS, and Seltzer MM, Parenting an Adult Child With Bipolar Disorder in Later Life, J Nerv Ment Dis., 197(5), 2009, 298-304.

[19] Awadalla AW, Ohaeri JU, Salih AA, Tawfiq AM, Subjective quality of life of family caregivers of community living Sudanese psychiatric patients, Soc Psychiatry Psychiatr Epidemiol., 40(9), 2005, 755-63.

[20] Bauer R, Gottfriedsen GU, Binder H, Dobmeier M, Cording C, and Hajak G, Spiessl H, Burden of Caregivers of Patients With Bipolar Affective Disorders, American Journal of Orthopsychiatry, 81(1), 2011, 139-148.

[21] Vieta E, Blasco-Colmenares E, Figueira ML, Langosch JM, Moreno-Manzanaro M and Medina E, Clinical management and burden of bipolar disorder: a multinational longitudinal study (WAVE-bd Study), BMC Psychiatry, 11, 2011, 5

[22] T Y G Van Der Voort, P J J Goossens, J J Van Der Bijl, Burden, coping and needs for support of caregivers for patients with a bipolar disorder: a systematic review, Journal of Psychiatric and Mental Health Nursing, 14(7), 2007, 679-687.

[23] Mueser KT, Webb C, Pfeiffer M, Gladis M, Levinson DF, Family burden of schizophrenia and bipolar disorder: perceptions of relatives and professionals, Psychiatr Serv., 47(5), 1996, 507-11. 